\title{
Oficinas ecopedagógicas na promoção da educação ambiental marinha
}

Ecopedagogical workshops in the promotion of marine environmental education

\author{
L. O. G. Moura ${ }^{1} ; \mathrm{J}$ Nilin${ }^{2} *$ \\ ${ }^{I}$ Departamento de Biologia,, Universidade Federal de Sergipe, 49100-000, São Cristóvaõ-Sergipe, Brazil \\ ${ }^{2}$ Departamento de Ecologia, Universidade Federal de Sergipe, 49100-000, São Cristóvaõ-Sergipe, Brazil \\ *jeamylle@gmail.com \\ (Recebido em 16 de julho de 2018; aceito em 27 de novembro de 2018)
}

\begin{abstract}
A fim de promover a Educação Ambiental Marinha com alunos do ensino fundamental, este trabalho apresentou como proposta a elaboração e aplicação de Oficinas Ecopedagógicas referentes aos problemas ambientais costeiros comuns ao estado de Sergipe. Foram propostas três oficinas que possuíam diferentes aplicações pedagógicas, as histórias em quadrinhos, o teatro com as mãos e o artesanato com materiais reutilizáveis. Com o intuito de comparar o efeito de um projeto de extensão voltado ao ensino de Ecologia Marinha, este trabalho aplicou as oficinas em duas diferentes turmas, uma destas já participara do projeto, enquanto a outra não. As oficinas se mostraram eficientes quanto à promoção da Educação Ambiental Marinha, e a turma que já participara de um projeto de extensão apresentou uma maior preocupação com o meio ambiente.

Palavras-chave: Sergipe, ecologia marinha, projeto de extensão.
\end{abstract}

In order to promote Marine Environmental Education with elementary school students, this paper presented as proposal the elaboration and application of Ecopedagogical Workshops regarding the coastal environmental problems common to the state of Sergipe. Three workshops were proposed that had different pedagogical applications, comics, theater with hands and crafts with reusable materials. In order to compare the effect of an extension project aimed at the teaching of Marine Ecology, this work applied the workshops in two different classes, one of them already participated in the project, while the other did not. The workshops were efficient in the promotion of Marine Environmental Education, and the group that had already participated in an extension project presented a greater concern with the environment.

Keywords: Sergipe, marine ecology, extension project.

\section{INTRODUÇÃO}

O modelo econômico utilizado principalmente pelos países ricos gerou graves problemas ambientais. Os crescentes níveis de poluição atmosférica dos grandes centros urbanos, a contaminação dos rios em consequência do despejo de resíduos industriais, a perda de cobertura vegetal do solo, são frutos desta economia que visa o consumo exacerbado pela população. Em meio a este quadro de grandes problemáticas ambientais foi apresentado na Conferência de Keele, no ano de 1965 na Grã-Bretanha, o termo Educação Ambiental (EA). Desde então, este tema foi abordado em diversas conferências mundiais, e se tornou referência na busca por um meio de vida mais sustentável e na elaboração de soluções para os problemas ambientais [1].

A EA busca sensibilizar as pessoas em relação ao mundo em que vivem, para que assim tenham uma melhor qualidade de vida, respeitando o ambiente que as cercam [2]. A partir disso é possível que o indivíduo desenvolva uma consciência ecológica em relação ao ambiente no qual está inserido, preservando-o de forma sustentável. A aquisição desta consciência depende intimamente da educação [3]. A educação acontece como parte da ação do homem de transformar a natureza em cultura, conferindo-lhe sentido, conduzindo-a para o campo da compreensão e da experiência humana de estar no mundo e fazer parte dele [4]. Para Assmann (2001) [5] "a educação terá um papel determinante na criação da sensibilidade social necessária para reorientar a humanidade".

Apesar do reconhecimento da educação como meio formador da consciência ecológica, a temática ambiental é pouco explorada no meio escolar. Muitas vezes a abordagem da EA nas 
escolas é feita de forma esporádica, com campanhas isoladas ou ações em datas comemorativas [6-9]. Além disso, muitos projetos voltados ao meio ambiente são elaborados sem embasamento na realidade local dos estudantes [6]. Por outro lado, os assuntos de maior relevância para os alunos são aqueles que envolvem o seu entorno, sua comunidade ou região, assim o contato com este meio mais acessível proporcionará a prática, onde o conhecimento se transforma em significado. Tópicos regionais relevantes devem ser explorados de forma mais intensa, para que durante o compartilhamento de ideias e opiniões, os estudantes se sintam mais responsáveis e atuantes no meio em que vivem [10].

$\mathrm{Na}$ procura pela aprendizagem da temática ambiental a partir da vida cotidiana, se destaca a Ecopedagogia, que pretende promover um novo olhar, um olhar mundial, uma maneira de pensar baseada em ações do dia-a-dia [3]. A Ecopedagogia, também denominada como Pedagogia da Terra ou Educação Sustentável, possui uma proposta pedagógica para a formação de uma sociedade sustentável, uma educação voltada ao respeito da natureza baseada em nossas atitudes diárias, procurando soluções para os problemas gerados pelo homem ao meio ambiente [11].

Para Halal (2009) [11], somente por meio de ações e reflexões da prática cotidiana é que se adquire saberes necessários para aprender a conhecer, a ser, a fazer e a conviver. Ao mesclar a Ecopedagogia com as oficinas pedagógicas é possível gerar a partir da prática cotidiana ações que reflitam o respeito pela natureza, visto que as oficinas pedagógicas procuram alcançar o conhecimento com base no conjunto de acontecimentos vivenciados no dia-a-dia, onde a prática e a teoria promovem o fundamento do processo pedagógico. Desta maneira, as oficinas aplicadas à educação são definidas como o lugar onde se aprende fazendo junto com os outros [12].

Neste estudo, as Oficinas Ecopedagógicas foram realizadas com crianças do ensino fundamental, onde foram trabalhados assuntos relacionados aos ambientes marinhos, que são comuns ao local da aplicação das oficinas. Segundo Berchez et al. (2007) [13], atividades relacionadas a educação ambiental marinha (EAM) são raras no Brasil, mesmo sendo de ampla importância no desenvolvimento de uma consciência voltada à conservação dos ecossistemas marinhos. Ainda segundo estes autores, apesar dos ecossistemas marinhos serem fonte de diversos recursos naturais, a EA exercida no Brasil é amplamente voltada aos ambientes terrestres.

Com o objetivo de analisar os efeitos do desenvolvimento de Oficinas Ecopedagógicas em duas turmas do ensino fundamental, este estudo procurou identificar as perspectivas dos alunos a respeito dos seus conhecimentos sobre os ambientes marinhos e a sua consciência ambiental a partir das conversas coletivas e das oficinas, avaliar a construção de significados adquiridos pelos participantes após a intervenção pedagógica, além de comparar as visões de duas turmas, das quais uma delas já participara de um projeto de extensão universitária sobre Educação Ambiental Marinha.

\section{PERCURSO METODOLÓGICO}

\subsection{Caracterização do público-alvo}

As oficinas foram desenvolvidas em 2016 com alunos do $5^{\circ}$ ano de uma escola municipal localizada próximo a Universidade Federal de Sergipe (UFS), no município de São Cristóvão, Sergipe. A escola atende aos anos iniciais do ensino fundamental, contando com cinco salas de aula, biblioteca, laboratório de informática, refeitório e quadra de esportes. Esta escola foi escolhida por participar do projeto de extensão da UFS, chamado EMANE - Ecologia Marinha na Escola. Uma das atividades do projeto é o curso de formação de Guardiões do Mar realizado durante cinco semanas, onde foram debatidos temas sobre cidadania e responsabilidade socioambiental, ciclo de vida de animais marinhos, pesca, turismo e poluição. O projeto EMANE foi criado em 2014, e desde então promove a divulgação científica de temas referentes à Ecologia Marinha entre alunos de graduação, estudantes da educação básica e jovens e adultos de comunidades pesqueiras do estado de Sergipe. A abordagem dos temas nas escolas se dá principalmente através de atividades lúdicas e artísticas, aplicadas por discentes de graduação da UFS, mas também conta com apoio de instituições locais como projeto Tamar, Reserva Biológica 
de Santa Isabel (Pirambu/SE), Fundação Mamíferos Aquáticos, Secretaria de Meio Ambiente de Aracaju, IBAMA, principalmente em palestras e debates para alunos de graduação.

Ao total, 17 crianças de ambos os sexos e com idades entre 10 e 13 anos participaram das oficinas. Destas, sete ainda não haviam participado do EMANE (Turma A) enquanto as outras 10 já eram Guardiões do Mar (Turma B). A fim de prover cuidados éticos com a pesquisa, foi solicitada a assinatura dos pais das crianças através de um termo de consentimento livre esclarecido, o qual permitia a participação dos seus filhos e assegurava que todos os dados só seriam utilizados para fins científicos.

\subsection{O delineamento da intervenção pedagógica}

A abordagem das oficinas seguiu os três momentos pedagógicos descritos em Delizoicov, Angotti e Pernambuco (2011) [14], que compreende: (i) a problematização inicial, em que através do diálogo e de questões relacionadas ao tema os alunos expõem o que pensam e vivenciam, neste primeiro momento a função do ministrante da oficina é de questionar tais posições levantadas pelos estudantes e de lançar dúvidas; (ii) a organização do conhecimento, é nesta etapa que o professor busca, em atividades variadas, apresentar uma compreensão científica das questões abordadas inicialmente, aqui as atividades utilizadas foram a conversa coletiva, apresentação de cartazes e dinâmicas; e (iii) aplicação do conhecimento, último momento pedagógico, destinado a analisar e interpretar as questões abordadas anteriormente, podendo servir também de trampolim para situações futuras, em que o conhecimento abordado anteriormente serve para o enfretamento destas questões.

Neste trabalho, as atividades lúdicas e os momentos pós-oficina serviram para aplicação do conhecimento abordado, onde os alunos produziram e interpretaram textos, além de gerarem discussões referentes ao tema. Assim, todas as três oficinas foram organizadas da seguinte forma: a) conversa coletiva a respeito do tema abordado; b) utilização de cartazes e, na segunda oficina, uma dinâmica para melhor compreensão da temática; c) aplicação das atividades e novamente uma conversa coletiva ao término destas. Os encontros tiveram a duração de uma hora aproximadamente, e ocorreram no turno da tarde durante o intervalo dos alunos, em uma sala de aula com apenas os participantes de cada grupo. As oficinas foram aplicadas em duas semanas totalizando seis dias, onde os primeiros três foram destinados a Turma A, e o restante a Turma B. Os conteúdos científicos abordados durante as oficinas foram obtidos principalmente a partir do livro de Biologia Marinha [15].

Oficina 1- "Era uma vez no Fundo do Mar". Esta oficina fez uma introdução à Ecologia Marinha e abordou as temáticas de biodiversidade marinha, ecossistemas marinhos e poluição. A atividade foi confeccionada a partir de um site da internet (http://www.toondoo.com/) que permite criar Histórias em Quadrinhos (HQ) de forma rápida e gratuita. Os balões de diálogo dos personagens marinhos (peixes, aves, mamíferos, tartarugas) foram deixados em branco para que os próprios alunos criassem o enredo da história. Os quadrinhos confeccionados foram impressos em folha A4 em escala de cinza e entregue aos alunos junto com cartolina, lápis grafite, tesoura sem ponta e cola branca, para que ao final eles confeccionassem um cartaz com a história.

Oficina 2 - "O Teatro das Aves". Nesta oficina os temas trabalhados foram a importância dos estuários, hábito alimentar e adaptação dos bicos de aves, espécies invasoras e a poluição nos estuários. Anteriormente à atividade, foi realizada uma dinâmica a partir da utilização dos seguintes materiais: uma bacia com areia da praia, conchas de bivalves, pedaços de barbante, um pegador de macarrão e uma pinça. Em seguida, a atividade de teatro com as mãos foi aplicada, e para esta foi necessária tinta guache de diversas cores, uma bacia com areia da praia e olhos de plástico para artesanato.

Oficina 3 - "Artesanato Marinho". Nesta oficina foram abordados os temas de reciclagem e reutilização de materiais, biodiversidade marinha, resíduos sólidos e poluição nas praias e oceanos. Foram confeccionados modelos de animais marinhos com materiais reutilizáveis, a partir de modelos observados na internet e adaptados para esta oficina, tais como peixes e estrelas do mar com garrafas PET e peixes com CD-ROM. Para o peixe de garrafa PET foi 
necessário tesoura, garrafa PET, estilete, E.V.A., cola colorida, cola quente, caneta esferográfica preta e olhos de plástico para artesanato.

\subsection{Procedimentos para a coleta e análise de dados}

Os encontros para o desenvolvimento das oficinas foram registrados com o auxílio de um gravador de áudio. As gravações constituem os resultados de cunho qualitativo deste trabalho, sendo analisados a partir das palavras e sons [16]. Os dados obtidos pelas gravações foram interpretados e conduzidos a partir da transcrição das informações coletadas, e avaliados por meio da análise de conteúdo proposta por Bardin (2011) [17]. Esta é caracterizada pela interpretação das comunicações por meio de procedimentos sistemáticos e objetivos de descrição do conteúdo da mensagem. A autora destaca três diferentes fases na análise do conteúdo: a pré-análise; a exploração do material; e o tratamento dos resultados, a inferência e interpretação.

A pré-análise corresponde à fase de organização dos dados, e foi dividida em cinco etapas: a leitura "flutuante", a escolha dos documentos, a formulação das hipóteses e dos objetivos, a referenciação dos índices e a elaboração dos indicadores e por fim a preparação do material. A fase de exploração do material consiste primordialmente na codificação, decomposição ou enumeração dos dados perante um princípio anteriormente elaborado. Com o intuito de proporcionar riqueza na interpretação das falas e alcançar os objetivos desse trabalho, esta etapa foi organizada em três categorias: (i) Conhecimento prévio dos alunos; (ii) Consciência ambiental dos alunos e (iii) Construção de significados após a oficina. Na última fase, que dispõe sobre o tratamento dos resultados, deve ser feito um estudo minucioso do material coletado, a reflexão crítica e a intuição do pesquisador são fundamentais para tornar os resultados significativos e válidos [17]. Em todas as categorias analisadas, os discursos das crianças da turma A e B foram confrontados a fim de observar as diferentes percepções das turmas. O item que se refere ao conhecimento prévio dos alunos tem como objetivo observar o conhecimento antes do contato com as oficinas, para isso foram feitas perguntas simples e curtas de caráter conceitual durante as conversas coletivas anteriores as oficinas, por exemplo, a definição de alguns termos usados na Biologia e a caracterização dos ambientes marinhos abordados em cada uma das oficinas. As falas que se referem à consciência ambiental dos alunos têm por finalidade apresentar as opiniões e relatos dos estudantes que remetam ao cuidado com o meio ambiente. $\mathrm{E}$ a última das categorias analisadas, construção de significados após a oficina, visa avaliar o conhecimento adquirido após as atividades realizadas com os alunos.

\section{RESULTADOS E DISCUSSÃO}

\subsection{Oficina 1 - Era uma vez no fundo do mar}

Com o intuito de avaliar o conhecimento prévio dos alunos acerca da temática ambiental marinha, a primeira oficina consistiu na criação de $\mathrm{HQ}$, onde as próprias crianças elaboraram as suas histórias a partir de quadrinhos que remetiam aos ambientes e a biodiversidade marinha. Segundo Vergueiro (2012) [18], as Histórias em Quadrinhos são uma grande fonte de aprendizado e proporcionam aos educadores inúmeras possibilidades. Ao total foram elaborados doze quadrinhos diferentes, tendo como personagens peixes e aves marinhas, e os ambientes das imagens representaram o fundo do mar e as praias (Figura 1A). A conversa coletiva referiu-se aos ambientes marinhos que as crianças conheciam, além da sua respectiva fauna. Para esta oficina, a turma foi dividia em três grupos com três alunos, onde cada um recebeu doze quadrinhos para que pudessem construir a sua história. Ao final, cada grupo confeccionou um cartaz com a sua história em quadrinho, que foi apresentada à toda turma. 

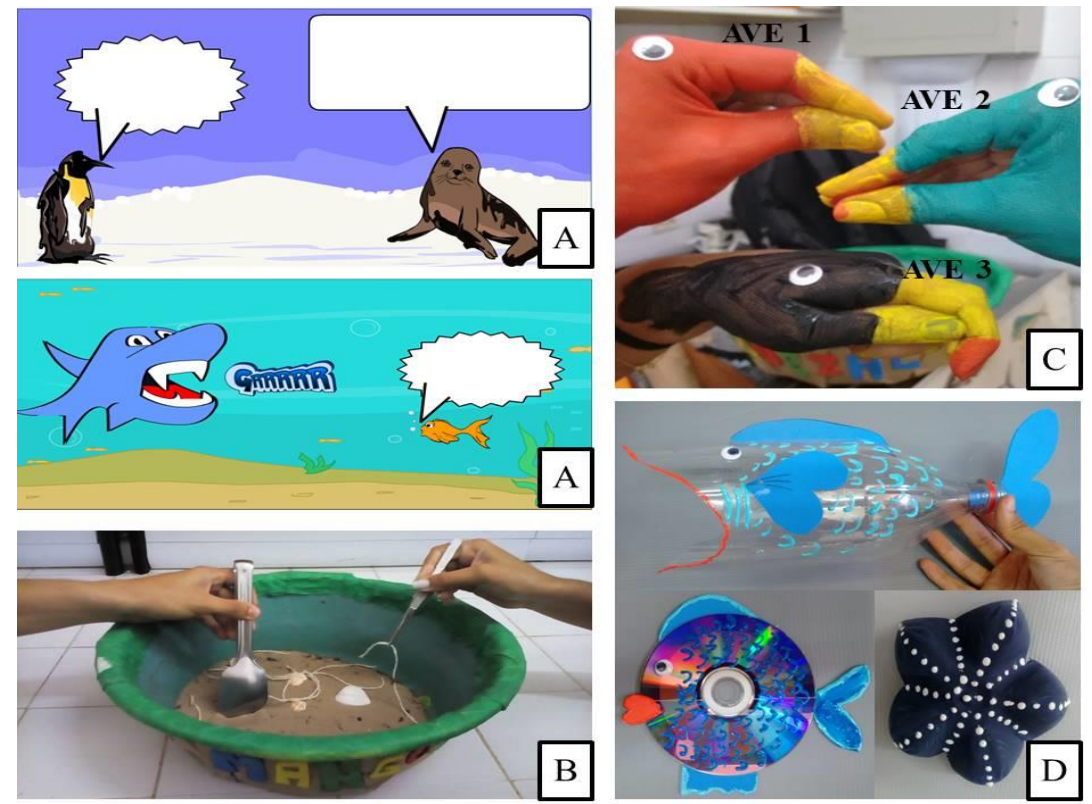

Figura 1: A - Quadrinhos confeccionados para oficina 1; B - Dinâmica realizada na oficina 2.; C - As três aves da peça de teatro pintadas nas mãos dos alunos. As aves 1 e 2 são as espécies nativas da região e possuem um mesmo tipo de bico. Já a ave 3, uma espécie invasora, possui um bico diferente; $D$ - Os materiais produzidos pelos alunos ao fim da oficina 3.

\subsubsection{Conhecimento prévio dos alunos}

Primeiramente os estudantes foram perguntados sobre o significado da palavra Ecologia, e em seguida foram convidados a citar alguns dos animais marinhos que eles conheciam ou já ouviram falar. Sobre a definição de Ecologia, apenas as crianças que já participaram do EMANE elaboraram respostas, apesar destas não refletirem o real significado da palavra. Uma das crianças associou o termo Ecologia à preservação do meio ambiente: "Cuidar da natureza se for fazer ecoturismo, se for viajar, se for conhecer a natureza, a ecologia é tipo cuidar da natureza, não desprezar a vida marinha" (Turma B). Outro aluno relacionou a Ecologia com a preservação da fauna: "Ecologia é cuidar dos animais" (Turma B). Esta relação entre a Ecologia e o cuidado com o meio ambiente pode estar associada ao curso de Guardiões do Mar oferecido pelo EMANE, neste curso os alunos participaram de atividades lúdicas voltadas à conservação ambiental marinha, a fim de conhecerem sobre a realidade socioambiental na qual estão inseridos. Os conteúdos abordados em sala de aula pelos professores, por vezes não são bem compreendidos pelos alunos ou não são relacionados ao cotidiano, fomentando o esquecimento deste conhecimento [19]. O tema Ecologia está proposto pela PCN do ensino de ciências [20] para o $5^{\circ}$ ano, porém é díficil precisar sobre o conteúdo abordado em sala de aula, já que não houve acompanhamento do professor em aulas pretéritas. Porém, pelo discurso apresentado pela turma A é possível inferir que o tema não ficou bem esclarecido.

Outra questão levantada durante a primeira oficina foi sobre a diversidade de animais encontrada em cada ambiente marinho, como as praias e os manguezais. Foi possível notar um maior conhecimento sobre a fauna desses locais a partir das respostas da Turma B, embora a Turma A também conhecesse alguns dos animais dessas localidades. Quando perguntados sobre os animais observados na praia, os alunos da Turma A responderam: "Tartaruga, estrela do mar", já as crianças da Turma B foram capazes de citar um maior número de animais "Tartaruga, caranguejo, bolacha da praia, estrela do mar, conchas". O mesmo se repetiu quando as crianças foram convidadas a dar exemplos de animais encontrados no manguezal: "Caranguejo, tartaruga, cobra, onça” (Turma A); "Caranguejo, peixe, camarão, guaiamum, siri" (Turma B). Uma das últimas atividades executadas pelo EMANE durante o curso de Guardiões do Mar, foi uma visita a Universidade Federal de Sergipe. Na UFS, os alunos participaram de uma aula prática, onde conheceram os animais marinhos da coleção científica, assim puderam observar de 
perto todos aqueles animais que tinham ouvido falar em sala de aula com o EMANE. Para Krasilchik (2008) [21], as aulas demonstrativas são importantes no processo de aprendizagem, pois garantem que todos os alunos observem o espécime simultaneamente, proporcionando um ponto de partida comum para uma discussão referente ao tema.

\subsubsection{Consciência ambiental dos alunos}

Durante a conversa coletiva com os estudantes, um cartaz foi exibido com imagens de animais e ambientes marinhos, que serviu para exemplificar os assuntos debatidos durante esta primeira oficina. Uma dessas imagens demonstrava uma praia poluída com petróleo, esta foi adicionada porque em alguns dos quadrinhos utilizados na oficina havia animais sujos de petróleo. Esta foto gerou bastantes comentários em ambas às turmas, embora nenhuma diferença significativa tenha sido percebida nas falas das crianças das duas turmas.

Os alunos afirmaram que o contato dos animais com o ambiente poluído com petróleo provocaria a morte dos mesmos, e que a causa da mortalidade dos animais se deve à sujeira causada pelo petróleo: "Porque o petróleo deixa tudo sujo" (Turma A), "Aparece peixe morto" (Turma B), "Professor, quem toma banho ai fica doente né" (Turma B). A similaridade na opinião dos alunos de ambas as turmas confere um conhecimento mútuo sobre este tema, visto que grandes vazamentos de petróleo são noticiados por diversas mídias.O rádio a televisão e a imprensa, constituem fontes de informação sobre o meio ambiente que atingem a maioria das crianças e das famílias. Entretanto, muitas vezes o assunto é abordado de forma superficial e equivocada, e concomitante ao discurso sócio-ambiental, os meios de comunicação podem disseminar o discurso inverso, se contrapondo às ideias propostas pela EA [10].

\subsubsection{Construção de significados após a oficina}

Neste item, as histórias em quadrinhos produzidas pelos alunos foram analisadas a fim de avaliar o conhecimento que os estudantes possuíam acerca da temática ambiental marinha. Segundo Barcelos (2006) [22], a interpretação e o enfrentamento dos problemas ecológicos vão além de uma análise gramatical, semântica, sintática, de conteúdo ou de discurso do mesmo. $\mathrm{O}$ autor ressalta a necessidade de que se ampliem alguns horizontes e se extrapolem os limites da compreensão baseados apenas no texto. Deste modo, a interpretação das representações inseridas nas imagens, sons e desenhos é crucial, elementos estes abundantes nas histórias em quadrinhos.

Foi possível observar muitos erros ortográficos nos textos produzidos pelos estudantes. Capellini et al. (2010) [23] ao analisarem as dificuldades de escrita de crianças do primeiro ciclo do ensino fundamental em uma escola pública, observaram erros gramaticais similares aos encontrados nas histórias em quadrinhos, como: a omissão e/ou a adição de letras, omissão de palavras, erros de acentuação e pontuação. Embora segundo os autores, a frequência dos erros diminua com a seriação dos alunos, erros como esses são normais para crianças nesses níveis de formação.

As crianças ficaram livres para criar as suas histórias de acordo com as imagens dos quadrinhos. Foi possível perceber uma maior intenção da Turma B em criar histórias relacionadas à poluição e ao descaso do ser humano ao meio ambiente, enquanto a turma $\mathrm{A}$ elaborou textos que expressassem a vida dos animais marinhos.

Na Turma A, muitas crianças escreveram sobre a relação de predação entre os animais, tendo o tubarão como o personagem mais temido: "Seu tubarão feio ouza mim comer" [sic], "Corre que o tubaro vai come os peixes" [sic], "Ei cara eu vou caí fora túbarão já tá vindo aí" [sic], "A socorro tubarão já tá vindo aí." [sic]. Além do tubarão, outros animais como a gaivota e a baleia tiveram seus diálogos associados à predação: "Amanhã eu vou comer aquele peixe que nadar para o fundo do mar eu juro que eu vou para casa de barriga cheia" [sic], texto que representa a fala de uma gaivota, "Eu estou com tamta fome que poderia comer um cardume de crius." [sic], frase de uma baleia presente em uma história em quadrinho da Turma A.

As crianças da Turma B elaboraram as suas histórias com um enfoque ambiental, utilizando da conversa coletiva prévia sobre a poluição causada pelo petróleo, além de comentarem muito 
sobre a poluição causada pelos resíduos e os seus efeitos no ecossistema marinho. Os quadrinhos fornecidos aos alunos continham imagens de alguns animais sujos com petróleo, e nestes diálogos os alunos escreveram: "Eu não gosto desse tal de petrólio ele deixa eu todo todo preto." [sic], "Agora eu não posso nem voar por causa desse pretólio" [sic], "Você viu o que eles esta falamdo que derubaram petrolhio no mar." [sic], "Olhar amigos cuidado derubaram petrolhio no mar eu quase que topo no petrolhio." [sic], "Plentrou esgaxa na nossa penas e não quossege virá" [sic]. Sobre a poluição causada pelos resíduos e a responsabilidade do ser humano nas questões ambientais os alunos escreveram: "Eu quase ia morrer por causa de uma bolsa de plástico" [sic], "Ajente esta doente de poluição no mar" [sic], "A praia estar com muito lixo" [sic], "Eu axo que vir um passario comendo junto lixo lá na praia axo que ele passou mal porque ele igulio uma garafa de platico." [sic], "Se eu pudesse falar a língua dos humanos eu mandava eles parar com isso" [sic], "É isso ai eu nem ninguém quer morrer. Por causa dos humanos." [sic], "É uma pena o ser humano destruir a natureza sabendo que vai prejudicar os animais que vivem procurando uma maneira de viver." [sic], "Nem pra eles serem um animal que vive no mar pra eles poderem ver o que nós enfrentamos aqui no fundo do mar." [sic].

Esta preocupação evidente das crianças da Turma B em demonstrar o descaso com o ambiente marinho pode estar diretamente associada à sua formação como Guardiões do Mar, uma vez que nessa formação os alunos participaram de atividades e discussões que proporcionaram a eles a formação de uma consciência ecológica. Ações educacionais como essa são indispensáveis, visto que para Gadotti (2001) [3], "a preservação do meio ambiente depende de uma consciência ecológica e a formação da consciência depende da educação".

\subsection{Oficina 2 - $O$ teatro das aves}

Voltada aos estuários, esta oficina apresentou as características gerais deste ambiente, além de discutir temas relacionados à ação antrópica nestas áreas com a finalidade de sensibilizar os estudantes às modificações ambientais causadas pela ação humana, e de como elas interferem na dinâmica natural do ambiente. Segundo Castro e Huber (2012) [15], os estuários são áreas semifechadas onde a água doce e a água do mar se encontram, e estão entre os ambientes que mais são afetados pelos seres humanos. São também áreas que possuem uma grande importância para muitas espécies de aves, pois servem como áreas de refúgio e alimentação para aves migratórias. Assim, esta oficina também falou sobre as aves deste ambiente, seus hábitos alimentares e diversidade morfológica dos bicos.

Diferentemente das outras duas oficinas, além da conversa coletiva com os estudantes, esta também contou com a utilização de uma dinâmica sobre os bicos das aves. A dinâmica consistiu em um experimento com objetos que simulavam diferentes bicos de aves e as suas respectivas presas. A pinça representava um bico longo e fino, apto a predar os pedaços de barbantes, que se assemelhavam a animais finos e alongados. Já o pegador de macarrão, o outro objeto que simulara um bico de ave, representava um bico mais robusto e avantajado, suas presas correspondiam a algumas conchas de bivalves presentes na dinâmica (Figura 1B). O objetivo desta atividade foi demonstrar como a diferença no formato dos bicos influencia diretamente na dieta do animal, assim diversas aves podem viver em um mesmo ambiente explorando diferentes recursos.

Logo após a dinâmica foi dado início a atividade de teatro com as mãos. O teatro é uma atividade muito motivadora para as crianças, pois os afeta nos aspectos emocional, cognitivo, motor e social. O teatro também mobiliza a atenção, a percepção e a memória, interpretação textual, a capacidade do improviso, trabalha a expressividade e a imaginação [24]. A realização desta atividade na escola é acima de tudo um instrumento de aprendizagem, devendo estimular o estudante a resolver conflitos relacionados ao ambiente escolar e social [25].

O texto escrito para a peça, conta a história de três aves, duas aves nativas da região e a outra ave invasora. As aves nativas, devido a ações dos humanos no ambiente, não conseguem mais encontrar o seu alimento como outrora e por conta de seus bicos altamente específicos àquelas presas, não são capazes de explorar outros recursos alimentares. Já a terceira ave, por ser uma espécie generalista, consegue prosperar em um ambiente altamente antropizado, e obtém o seu alimento a partir dos restos de comida deixados pelos humanos. A peça termina com as espécies 
nativas fugindo à procura de alimento, enquanto a espécie invasora permanece e prospera no local. $\mathrm{O}$ cenário utilizado para a peça foi àquele mesmo balde da dinâmica dos bicos das aves. Apesar do roteiro da peça exigir apenas três atores e mais um narrador, todas as crianças da turma participaram. Algumas crianças atuaram na peça, outras ajudaram na pintura das mãos dos atores e na organização do cenário, além de fazerem parte da plateia. As mãos dos atores foram pintadas com tinta guache, as cores das aves eram determinadas pelos próprios alunos, embora os bicos possuíssem a mesma cor amarela (Figura 1C). A principal diferença entre as aves nativas e a espécie invasora era o seu bico, que na espécie invasora era mais pontiagudo, o que lhe permitia explorar os diversos recursos presentes no ambiente.

\subsubsection{Conhecimento prévio dos alunos}

Por conta do pouco tempo disponível para a conversa coletiva com a Turma A, só foi possível debater a respeito do manguezal. Deste modo, no que diz respeito a esta categoria, apenas as falas sobre o ambiente em questão foram comparadas.

Inicialmente as crianças de ambas as turmas foram perguntadas sobre os aspectos gerais do manguezal, e as respostas elaboradas para esta questão foram bem parecidas: "E cheio de árvore um pouco de lama e tem uns caranguejos peixinhos" (Turma A), "Nem tão salgado nem tão doce" (Turma B). Em relação à água do manguezal os alunos disseram: "É misturada" (Turma A), "Porque se mistura a água do rio com a da praia" (Turma B).

Esta similaridade e congruência nas respostas dos alunos demonstram a existência de um conhecimento prévio acerca do tema, segundo Ausubel (2000) [19], o conhecimento prévio é um fator determinante no processo de aprendizagem, onde a interação entre os novos significados potenciais e ideias relevantes na estrutura cognitiva do aprendiz, ou seja, o seu conhecimento prévio dá origem a significados verdadeiros ou psicológicos A construção de significado durante o processo de aprendizagem das questões ambientais é fruto da possibilidade de estabelecer ligações entre o que aprende e o que já se conhece, e também da possibilidade de utilizar este conhecimento em outras situações. Por isso, o convívio escolar é um fator crucial para a aprendizagem de valores e atitudes, pois a escola é um dos ambientes mais imediatos do aluno, assim a partir do próprio cotidiano da vida escolar ocorre à compreensão das questões e atitudes ambientais [10]. Deste modo, a familiaridade dos alunos com o tema possibilitou a elaboração de respostas coerentes, visto que o manguezal é um ecossistema comum no litoral do estado de Sergipe, incluindo o município de São Cristóvão [26].

$\mathrm{Na}$ atividade que buscou demonstrar como os diferentes bicos das aves influenciam na sua alimentação, os alunos se mostraram bastante interessados e curiosos, foi possível perceber que a atividade provocou uma melhor compreensão do assunto, tendo em vista as respostas das crianças. Quando perguntados sobre a necessidade das diferenças nos bicos das aves, uma criança respondeu: "Pra se alimentar de cada coisa" (Turma B). Outro aluno afirmou que a falta de algum dos alimentos presentes na atividade acarretaria na morte de uma das aves: "Ele morre porque não vai ter alimento" (Turma B). Atividades lúdicas como essa provocam um maior interesse do aluno, e são capazes de facilitar a compreensão do assunto, Kishimoto (2009) [27] atenta para a importância da utilização de atividades lúdicas em busca de uma melhor aprendizagem.

\subsubsection{Consciência ambiental dos alunos}

Para esta categoria apenas foi possível discutir dados da Turma $B$, tendo em vista o pouco tempo disponível para a conversação com a Turma A. Durante a conversa com as crianças, a poluição no manguezal foi o principal tema abordado, sendo a poluição causada pelos resíduos, a principal citada pelos estudantes: "Já vi bolsa, copo de plástico" (Turma B). Apesar deste ambiente ser afetado por outros tipos de poluentes, como o despejo de esgotos industriais e domésticos, óleo e até mesmo por metais pesados como o mercúrio, por exemplo [28-29], as crianças foram capazes de citar apenas os resíduos sólidos, principalmente plástico. Esta percepção pouco abrangente deve-se ao fato dos resíduos sólidos serem os poluentes com um 
maior apelo visual, e, além disso, serem assunto frequente na EA trabalhada em sala de aula, sendo a sua abordagem proposta pelo PCN do meio ambiente [10]. Quando perguntados sobre os responsáveis pela poluição deste ambiente, as crianças prontamente falaram: "Nós", "O povo" (Turma B). Durante o curso de Guardiões do Mar, essas crianças tomaram partido da responsabilidade humana nas questões ambientais, e perceberam que o homem também faz parte da natureza. Este reconhecimento do papel da sociedade nas questões ambientais é crucial, visto que apenas através da ação integrada da sociedade é que a degradação ambiental pode ser combatida [3]. Para Cuba (2010) [30], projetos que envolvam os alunos em sala de aula fomentam o surgimento de multiplicadores de atitudes sustentáveis, estes trabalhos pedagógicos devem focar nas realidades da vida social mais imediatas, para que assim, através da EA se desenvolva uma conscientização focada no interesse do aluno pela preservação.

\subsubsection{Construção de significados após a oficina}

Ao final da atividade de teatro, as crianças debateram sobre o enredo da história. Em seus discursos, os alunos de ambas as turmas conseguiram resumir bem os pontos principais da história e acertaram ao elencar os fatores responsáveis que fizeram com que a peça terminasse com a saída das espécies nativas do ambiente. Sobre o que aconteceu ao fim da história, os alunos disseram: "Ele tomou o nosso lugar" (Turma A), apontando para o aluno que representou a ave invasora: "As aves não tinham o que comer" (Turma B), "João tinha os restos de comida" (Turma B), "O João pode comer tudo que ele ver pela frente" (Turma B), visto que o João fora a criança que fizera o papel da ave invasora. O nome fictício "João" foi adotado no manuscrito para manter o anonimato do participante da oficina por questões éticas. "Os turistas e humanos acabaram com tudo" (Turma B), "Por causa daqueles humanos miserável que tomaram o nosso lugar de nós" (Turma A). Uma criança apontou como ensinamento que pode ser extraído da história: "Que a gente não pode destruir as coisas dos animais" (Turma $\mathrm{B}$ ).

Estas interpretações corretas que os alunos deram ao final da oficina expressam a eficácia da utilização do teatro no aprendizado, visto que o teatro pode ser um recurso muito importante para a compreensão de temas atuais relevantes, como é o caso da temática ambiental [31]. Além disso, o teatro é uma ferramenta que pode ser aplicada para diferentes objetivos voltados à educação, pois contribui para o aprendizado no uso da linguagem, na mobilização da imaginação e da criatividade. E, por ser um universo peculiar de interação social e de manifestação da cultura, é capaz de alcançar diferentes objetivos [24].

\subsection{Oficina 3 - Artesanato marinho}

A fim de promover a sensibilização dos alunos referente à importância dos processos de reciclagem e reutilização dos resíduos sólidos, esta última oficina consistiu na confecção de modelos de peixes e estrelas do mar a partir de materiais reutilizáveis (Figura 1D). Segundo Mattos e Granato (2009) [32], a reciclagem consiste na devolução do material utilizado para um novo ciclo de produção, este processo reduz a extração de matéria-prima necessária na produção de novos materiais. Já a reutilização, prolonga a vida útil ou atribui novo uso a algo que seria descartado. $\mathrm{O}$ uso incorreto desses dois termos é muito frequente, visto que, muitos recursos educativos como livros didáticos e paradidáticos tratam-os como sinônimos [33]. Os materiais utilizados para esta oficina foram previamente preparados a fim de reduzir a utilização de instrumentos cortantes pelas crianças, deste modo as garrafas PET e o EVA foram levados à escola já recortados. O uso desses materiais na confecção de recursos didáticos oferece um destino alternativo a vários resíduos que seriam descartados e, sobretudo, sensibiliza as pessoas para a diminuição da produção de resíduos e a sua reutilização [29]. 


\subsubsection{Conhecimento prévio dos alunos}

A conversa coletiva durante esta oficina se resumiu a poluição das praias e a consequência dos resíduos na vida marinha, além das diferenças entre reciclagem e reutilização. Inicialmente, perguntou-se as crianças sobre o que elas encontram na areia quando vão à praia, embora muitos seres vivos possam ser encontrados neste ambiente, os alunos disseram que avistavam "Lixo" (Turma B), sendo citados "Vasos" (Turma A), "Coco, casca de banana, lata de cerveja, lata de refrigerante" (Turma B). Ainda durante a conversa sobre este assunto, os alunos da Turma B lembraram que o resíduo pode ser transportado de várias maneiras, "Pelo ar, pelo vento, pelos animais".

Sobre a diferença entre os conceitos de reciclagem e reutilização, as crianças de ambas as turmas conseguiram através de exemplos, exporem a definição dos dois termos: "Reutilizar é pegar uma garrafinha de refrigerante e usar novamente para encher de água" (Turma A), "Botar planta dentro da garrafa" (Turma B). Sobre a reciclagem, os alunos disseram: "Reciclar é pegar esse plástico e fazer outra coisa com ele" (Turma A), "Usar papel, lixo pra fazer alguma coisa" (Turma B). Uma das crianças da Turma A, respondeu: "Reciclar é vender", pois o seu pai trabalhava como catador de resíduos e vendia o que coletava as empresas de reciclagem. Para Vigotsky (2004) [34], a educação se faz através da própria experiência do aluno, que é totalmente determinada pelo meio. Neste caso, a profissão do pai da criança, fez com que ela associasse o processo de reciclagem a uma forma de geração de renda. Nesse momento foi possível perceber que apesar dos alunos terem consciência de que alguns materiais podem ser reciclados ou reutilizados, o termo lixo ainda é bastante referido, e de acordo com Demajorovic (1996) [35] este termo deve ser aplicado apenas para materiais que não são passíveis de reciclagem ou reutilização.

\subsubsection{Consciência ambiental dos alunos}

Durante a conversa coletiva, imagens de praias completamente poluídas e animais que acidentalmente consumiram resíduos sólidos, foram mostradas às crianças, entre os animais presentes nas imagens estavam uma tartaruga com uma sacola plástica na boca e uma ave em decomposição que possuía resíduos na região do estômago. Sobre isso, os alunos falaram: "Ela pensa que o plástico é água viva" (Turma A), "Comeu uma bolsa plástica porque pensou que era uma água viva" (Turma B), "O passarinho pode ter comido o lixo pensando que era um peixe" (Turma A). Apesar dos alunos da Turma B estarem mais familiarizados com o tema, devido as experiências proporcionadas a partir do curso de Guardiões do Mar, ambas as turmas conseguiram deduzir o que tivera acontecido com aqueles animais. A utilização das imagens para este debate pode ter facilitado a compreensão das questões em discussão, Silva et al. (2006) [36] atenta para a importância das imagens no ensino de ciências, embora segundo ele, a sua compreensão não seja imediata, tornando-se necessário a interferência de um mediador. $\mathrm{Na}$ conversa com os alunos, a construção de significados ocorreu de maneira gradual, de forma que as imagens atuaram como catalizadores da aprendizagem, além de se tornarem elementos para o debate.

\subsubsection{Construção de significados após a oficina}

Ao término da oficina, as crianças demonstraram conhecer a importância tanto da reciclagem quanto da reutilização, quando perguntados sobre o que é possível fazer com os resíduos que produzimos, um aluno falou: "Pode reciclar e reutilizar" (Turma B), outra criança disse: "Lugar de lixo é no lixo" (Turma A). E a respeito das consequências do descarte inadequado de resíduos sobre o ambiente marinho, os alunos disseram: "Vai prejudicar a vida dos animais" (Turma B), "Prejudica o ambiente marinho" (Turma A). A utilização de elementos lúdicos com materiais reutilizáveis promove a sensibilização e a discussão da relação do homem com o meio ambiente, além de tornar a aprendizagem mais agradável e eficiente. Quando o conhecimento é produzido de forma coletiva, como foi o caso desta oficina, proporciona o aprofundamento da reflexão sobre 
a Educação Ambiental, fazendo com que os alunos reaproveitem materiais que seriam descartados de forma inadequada [31].

\section{CONCLUSÃ̃o}

Todos os participantes das oficinas sentiram-se capazes de opinar sobre os assuntos debatidos durante os encontros, e foi possível notar também o engajamento e a preocupação nas questões ambientais entre os alunos de ambas as turmas. Embora todas as oficinas desenvolvidas tenham tratado de assuntos pertinentes à Educação Ambiental Marinha e viabilizado o debate e a sensibilização sobre as temáticas ambientais, as duas primeiras (Histórias em quadrinhos sobre ambientes e biodiversidade marinha; Teatro sobre aves estuarinas) obtiveram um sucesso maior em relação aos discursos expressos pelas crianças. A realização de atividades que contribuam com a imaginação e a criatividade das crianças estimulam uma participação mais ativa dos alunos, gerando debates mais envolventes e resultados mais expressivos. Além disso, a utilização de temas que fogem um pouco dos assuntos abordados comumente em sala de aula provocam a curiosidade e um maior envolvimento dos alunos.

Durante o decorrer das oficinas foi observado o conhecimento dos alunos referentes a tais temáticas, sendo possível concluir que o conhecimento prévio serviu de base para a construção de uma percepção ambiental mais voltada ao seu entorno. Contudo, as crianças da Turma B, por já terem participado de um projeto de cunho ambiental como o EMANE, possuíam uma consciência ambiental mais apurada e um conhecimento mais profundo sobre o tema. Assim, é possível afirmar que projetos como EMANE são importantes meios para a promoção da EA, uma vez que buscam a sensibilização e protagonismo dos estudantes acerca das questões ambientais.

\section{AGRADECIMENTOS}

Os autores gostariam de agradecer aos estagiários do projeto EMANE (2015/2016) que contribuíram de alguma forma para realização destas oficinas, em especial Andreza do Nascimento Oliveira e Laize dos Santos. Um agradecimento especial à diretora, à professora e aos alunos que participaram desta pesquisa. A Pró-Reitoria de Extensão da UFS (PIBIX 2015/2016) e MEC/SESu pelo apoio institucional e financeiro (Processo 4065.2.2823.14042014).

\section{REFERÊNCIAS BIBLIOGRÁFICAS}

1. Dias GF. Educação ambiental: princípios e práticas. 9ed. São Paulo: Gaia; 2004.

2. Mansano CN. A escola e o bairro: Percepção ambiental e interpretação do espaço de alunos do ensino fundamental [dissertação]. Maringá (PR): Universidade Estadual de Maringá; 2006. 170p.

3. Gadotti M. Pedagogia da terra: Ecopedagogia e educação sustentável. In: Paulo Freire y la agenda de la educación latino-americana em el siglo XXI. Buenos Aires: CLASCO, Consejo Latinoamericano de Ciencias Sociales, 2001. p. 81- 132.

4. Carvalho ICM. Educação ambiental: a formação do sujeito ecológico. 6ed. São Paulo: Cortez; 2012.

5. Assmann H. Reencantar a educação: rumo à sociedade aprendente. 5ed. Petrópolis: Vozes; 2001. 251p.

6. Brasil.Ministério da Educação. Programa parâmetros em ação, meio ambiente na escola: guia do formador. Brasília: MEC/ SEF; 2001.

7. Medina NM. A formação dos professores em Educação Ambiental. In: Brasil.Secretaria de Educação Fundamental. Panorama da Educação Ambiental no Ensino Fundamental. Brasília: MEC/SEF; 2001. p. 17-24.

8. Leme TN. Conhecimentos práticos dos professores e sua formação continuada: um caminho para a educação ambiental na escola. In: Guimarães M. (Org.). Caminhos da Educação Ambiental: da forma à ação. Campinas (SP): Papirus; 2010. p. 87-112.

9. Guimarães M. A formação de educadores ambientais. Campinas (SP): Papirus; 2012. 174p.

10. Brasil. Secretaria de Educação Fundamental. Parâmetros curriculares nacionais: meio ambiente, saúde. Brasília: MEC/SEF; 1997.

11. Halal CY. Ecopedagogia: uma nova educação. Rev Educ. 2009;12(14):87-103. 
12. de Figueirêdo MAC, da Silva JR, Nascimento ES, de Souza V. Metodologia de Oficina Pedagógica: Uma Experiência de Extensão com crianças e adolescents. Rev Eletro Ext Cid. 2006;2:1-12.

13. Berchez F, Ghilardi N, Robim MJ, Pedrini AG, Hadel VF, Fluckiger G, Bespalec P. Projeto trilha subaquática: sugestão de diretrizes para a criação de modelos de Educação Ambiental em unidade de conservação ligadas a ecossistemas marinhos. 2007 Dez;7(3):181-209.

14. Delizoicov D, Angotti JD, Pernambuco MM. Ensino de Ciências: fundamentos e métodos. 4ed. São Paulo: Cortez; 2011.

15. Castro P, Huber M. Biologia Marinha. 8ed. AMGH Editora; 2012.

16. Moreira DA. O Método Fenomenológico na Pesquisa. São Paulo: Pioneira Thomson Learning; 2004.

17. Bardin L. Análise de conteúdo. São Paulo: Edições 70; 2011. 279p.

18. Vergueiro W. Uso das HQS no ensino. In: Barbosa A, Ramos P, Viela T, Rama A, Vergueiro W. Como usar as Histórias em Quadrinhos na sala de aula. 4ed. São Paulo: Contexto; 2012. p.7-29.

19. Ausubel DP. Aquisição e retenção de conhecimentos: Uma perspectiva cognitiva. 1ed. Lisboa: Plátano Edições Técnicas; 2000.

20. Brasil. Secretaria de Educação Fundamental. Parâmetros curriculares nacionais: ciências naturais. Brasília: MEC/SEF; 1998. 138p.

21. Krasilchik M. Prática do Ensino de Biologia. 4ed. São Paulo: Editora da Universidade de São Paulo; 2011. 199p.

22. Barcelos VHL. Educação Ambiental, Representações Sociais e Literatura: um Estudo a Partir do Texto Literário de Octávio Paz. In: Sato M, Santos JE. A Contribuição da Educação Ambiental à Esperança de Pandora. São Carlos: RiMa; 2006. p.479-495.

23. Capellini SA, Butarelli APKJ, Germano GD. Dificuldades de aprendizagem da escrita em escolares de $1^{\mathrm{a}}$ e $4^{\mathrm{a}}$ series do ensino público. Rev Educ em Quest. $2010 \mathrm{Jan} / \mathrm{Abr}$;37(23):146-164.

24. de Oliveira ME, Stoltz T. Teatro na escola: considerações a partir de Vygotsky. Educ em Rev. 2010 Nov/Jan;(26):77-93, doi:10.1590/S0104-40602010000100007.

25. Miranda JL, Elias RC, Faria RM, da Silva VL, Felício WAS. Teatro e Escola: funções, importâncias e práticas. Rev CEPPG-CESUC. 2009;(20):172-181.

26. de Araujo SI, da Silva GH, Muehe D. Mapas de sensibilidade ambiental a derrames de óleo: Ambientes costeiros, estuarinos e fluviais. Rio de Janeiro: Petrobras; 2006.

27. Kiskimoto TM. O brincar e suas teorias. 4ed. São Paulo: EDUSP; 2008. 197p.

28. Alves JRP. Manguezais: educar para proteger. Rio de Janeiro: Femar: Semads; 2001. 96p.

29. Oliveira MLJ, Vidal-Torrado P, Otero XL, Ferreira JR. Mercúrio total em solos de manguezais da Baixada Santista e Ilha do Cardoso, Estado de São Paulo. Química Nova. 2007 Jan;30(3):519-524.

30. Cuba MA. Educação ambiental nas escolas. ECCOM. 2010 Jul/Dez;1(2):23-31.

31. Camarotti MF, Cruvinel SRC, de Lacerda AT. Educação Ambiental e a Construção de Fantoches com Materiais Reutilizados. In: Abílio FJP, Florentino HS. Educação Ambiental: da Pedagogia Dialógica e Sustentabilidade no Semiárido. João Pessoa: Editora da UFPB; 2014. p.165-184.

32. de Mattos NS, Granato SF. Lixo: problema nosso de cada dia: cidadania, reciclagem e uso sustentável. São Paulo: Saraiva; 2009. 64p.

33. Cinquetti HS. Lixo, resíduos sólidos e reciclagem: uma análise comparative de recursos didáticos. Educar em revista. 2004 Abr;(23):307-333.

34. Vygotsky LS. Psicologia pedagógica. São Paulo: Martins Fontes; 2004.

35. Demajorovic J. A evolução dos modelos de gestão de resíduos sólidos e seus instrumentos. São Paulo: Cadernos Fundap. 1996;20:47-58.

36. da Silva HC, Zimmermann E, Carneiro MHS, Gastal ML, Cassiano WS. Cautela ao usar Imagens em Aulas de Ciências. Cien e Educ. 2006 Set/Abr;2(2):219-233, doi:10.1590/S1516-73132006000200008. 